\title{
Durability of Tubular Geopolymer Reinforced with Silica Sand
}

\author{
Monique Tohoué Tognonvi, Julien Soro, Sylvie Rossignol
}

Groupe d'Etude des Matériaux Hétérogènes, CEC, Ecole Nationale Supérieure de Céramiques Industrielles, Limoges, France. Email: Sylvie.rossignol@unilim.fr

Received November $15^{\text {th }}, 2011$; revised December $13^{\text {th }}, 2011$; accepted December $23^{\text {rd }}, 2011$

\begin{abstract}
Metakaolin-based geopolymer materials reinforced with sand in tubular shape were developed, and their durability in acidic, neutral and humid environment was investigated. Results show that mechanical properties of materials are not affected by durability tests suggesting a good stability in aqueous media. Furthermore, the surface of samples which was covered by soluble species such as $\mathrm{KOH}$ or $\mathrm{K}_{2} \mathrm{CO}_{3}$ becomes smooth after treatment in acidic and neutral media and appears not to be attacked confirming the high acid resistance of geopolymer materials.
\end{abstract}

Keywords: Metakaolin-Based Geopolymer Materials; Tubular Shape; Durability Tests; Aqueous Media

\section{Introduction}

Geopolymer materials are known to have high stability in aggressive environment such as acidic medium [1,2]. This property is strongly dependent on their chemical composition that includes low-calcium compounds. Actually, many investigations have reported that less $\mathrm{Ca}$ content in geopolymer materials makes them more durable in acid environment than ordinary Portland cement which is a Ca-rich product [2-4], as the presence of calcium would be expected to lead to the formation of calcium silicate hydrates which have lower resistance to acid attack than the alkali aluminosilicate structure of geopolymers [5]. Due to their good acid resistance, geopolymers have drawn more attention recently and seem to be an alternative to the acid corrosion of Portland cement. The formation of geopolymer materials which results from alkali-activation of aluminosilicates with alkaline silicate solutions is largely described in literature [1, 2,6]. However, Lloyd et al. [7] have reported results which contradict the high acid resistance in such materials. They have shown that the high-calcium fly ash was significantly more resistant to acid attack than any low calcium ashes. This could be related to the fact that the porosity and ionic permeability of geopolymer containing calcium is lower than that of samples with little or no calcium evidenced by previous work which applied Wood's metal intrusion porosimetry to the analysis of undamaged geopolymer materials [8].

Moreover, the behavior of these materials in aqueous medium (acid or neutral environment) also depends on their formulation in relation with the $\mathrm{Si} / \mathrm{Al}$ molar ratio and the nature of the alkali cation ( $\mathrm{Na}$ or $\mathrm{K}$ ). Metakaolinbased geopolymer materials can be either damaged or stable in aqueous medium depending on the formulation $[1,9]$ or on the intrinsic ordering of the components within the aluminosilicate gel $[2,10]$. The increase in silica content and the reduction of the amount of acidsoluble material, i.e. alkali cation (sodium or potassium), calcium and aluminum would enhance the acid resistance of geopolymers [5]. It has also been shown that the nature of the cation affects the eventual morphology with $\mathrm{K}$ seemingly responsible for a higher degree of condensation when compared to $\mathrm{Na}$ under the same conditions. Matrixes containing $\mathrm{K}$ had higher compressive strengths but also higher specific surface area values and proved to have a lower degree of crystallinity as well as a lower resistance to attack by $\mathrm{HCl}[11,12]$.

Recent investigations on the use of metakaolin-based geopolymer materials in inorganic foam preparation has allowed to optimize the formulation at $\left(\mathrm{K}_{0.1}\left(\left(\mathrm{SiO}_{2}\right)_{1.33} \mathrm{AlO}_{2}\right)_{0.15}\right.$, $0.71 \mathrm{H}_{2} \mathrm{O}$ ) [13]. The purpose of this work is first, to use this formulation in the development of geopolymer of tubular-shaped reinforced by the addition of silica sand at $50^{\circ} \mathrm{C}$ which could be used in fuse technology as fuse body and then, to study the durability in aqueous media (acid and neutral) and humid environment (85\% humidity) of these materials in order to provide our contribution in the numerous studies on the corrosion of geopolymer through compressive strength tests, SEM observations and elementary chemical analysis. 


\section{Experimental Part}

\subsection{Materials and Preparation of Tubes of Geopolymers}

The features of raw materials and their corresponding mass composition used to manufacture geopolymer material are provided in Table $\mathbf{1}$.

The geopolymer material was prepared from a solution containing dehydroxylated kaolinite (metakaolin) and $\mathrm{KOH}$ pellets $(85.7 \%$ of purity) dissolved in potassium silicate $(\mathrm{Si} / \mathrm{K}=1.66$, density 1.33$)$ into which $12 \mathrm{wt} \%$ of sand were added, as described in Figure 1. The reactive mixture obtained after $5 \mathrm{~min}$ mixing was then poured into in sealed tubular molds $(13 \times 11 \times 47 \mathrm{~mm})$ and allowed to cure in an oven at $50^{\circ} \mathrm{C}$ for $17 \mathrm{~h}$. After curing, the tubes were extracted from the molds and were subjected to the durability tests before their characterizations.

\subsection{Durability Tests}

Groups of ten samples were placed in hermetic plastic boxes of square shape containing distilled water and hydrochloric acid (0.01 $\mathrm{M} ; \mathrm{pH}=2)$. Boxes were maintained at room temperature throughout the tests which last 24 days. The $\mathrm{pH}$ value of solutions was measured all along the test using a pHM240 METERLAB pHmeter (radiometer). At the end of the test, the tubes were extracted from the different solutions, allowed to dry at room temperature for $48 \mathrm{~h}$, weighed and characterized. Solutions were analyzed by ICP-AES to identify the chemical elements which pass in solution. Another group of ten samples was maintained in a controlled atmosphere with humidity of $85 \%$ in order to study the ability of the samples to regain moisture. This relative humidity was obtained in a glass desiccator containing a saturated solution of $\mathrm{KCl}$ at $20^{\circ} \mathrm{C}$ during 24 days. The weight gain of samples was monitored as a function of time with a scale. After the treatment, samples were subjected to the different characterizations.

\subsection{Characterization Techniques}

The K, Al and Si concentrations in the solutions obtained after immersion tests were determined using a Thermo
Jarrell Ash Corporation IRIS spectrometer (ICP-AES).

Mechanical properties were characterized using compressive strength tests. The compressive strength test of samples was determined on tubular specimens $13 \times 11 \times$ $47 \mathrm{~mm}$ in size using a JJ LLOYD apparatus (Ref. EZ20) material testing machine at room temperature with $20 \mathrm{kN}$ as the load frame and a strain rate of $1 \mathrm{~mm} \cdot \mathrm{min}^{-1}$. The tubular samples have a length/external diameter ratio of 2 and about ten samples were prepared to obtain an efficient reproducibility.

After the durability tests, the microstructure of the surface of samples were metalized by coating with platinum in an evaporator vacuum and observed using a Cambridge instruments microscope. Observations were realized with an accelerating voltage of $15 \mathrm{kV}$.

\section{Results and Discussion}

When samples undergo an aggressive treatment by immersion in acidic or neutral environment, the $\mathrm{pH}$ value of the aggressive solution increases strongly from the first day to reach a maximum value of about 11 (Figure 2). This value is reached more rapidly as the initial value of the $\mathrm{pH}$ is high. Actually, for a solution of $\mathrm{pH} 7$ (distilled

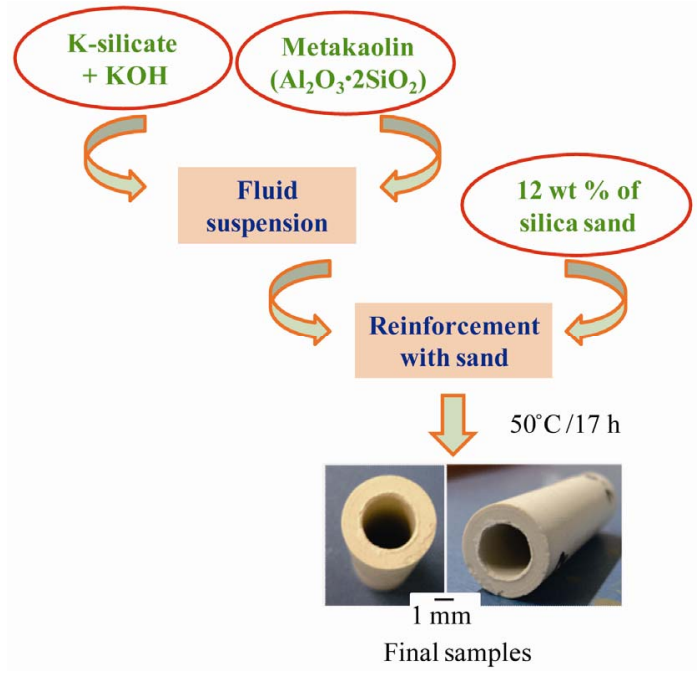

Figure 1. Formation process of tubes of metakaolin-based geopolymer materials reinforced with $12 \mathrm{wt} \%$ of sand and cured at $50^{\circ} \mathrm{C}$ for $17 \mathrm{~h}$.

Table 1. Feature of raw materials and their corresponding mass composition used to manufacture the metakaolin-based geopolymer material.

\begin{tabular}{|c|c|c|c|}
\hline Raw materials & Characteristics of materials & Supplier & Mass composition of geopolymer (\%) \\
\hline Potassium silicate solution & $3.8 \mathrm{SiO}_{2} \cdot \mathrm{K}_{2} \mathrm{O} \cdot 50 \mathrm{H}_{2} \mathrm{O} ; \mathrm{d}=1.2$ & Chem-Lab & 43.82 \\
\hline Metakaolin & $\mathrm{Al}_{2} \mathrm{O}_{3} \cdot 2 \mathrm{SiO}_{2} ; \mathrm{D} 50=5.3 \mu \mathrm{m}$ & AGS company & 33.97 \\
\hline Sand & $98.4 \% \mathrm{SiO}_{2} ; \mathrm{D} 50=90 \mu \mathrm{m} ;$ a-quartz & SIBELCO & 12.00 \\
\hline
\end{tabular}


water), the maximal value ( $\mathrm{pH} 11)$ is achieved only few minutes ( $\sim 5 \mathrm{~min})$, whereas for the acidic solution ( $\mathrm{pH} 2)$, the maximal value is obtained after $5 \mathrm{~h}$.

The rapid raise of the $\mathrm{pH}$ value of solutions indicates the removal of basic species from the surface of samples into the solution. This result is in accordance with that observed by Vance et al. [14] and Aly et al. [9] who have shown that the $\mathrm{pH}$ of the leaching solution increases rapidly and stabilizes at values $>10$ within ten $\min$ at $90^{\circ} \mathrm{C}$. These authors attributed the increase of the $\mathrm{pH}$ value to the release of alkali cation in the solution. Assuming that the rate of basic species release is expressed like $\left[\mathrm{H}^{+}\right] / \mathrm{t}$ ratio, it was determined according to the nature of the aggressive solution. This rate equals to 2 and $0.004 \times$ $10^{-1} \mathrm{mmol} / \mathrm{l} / \mathrm{h}$ for acid solution and distilled water respectively suggesting a higher rate of release when decreasing the $\mathrm{pH}$ value. This could be related to the great affinity of $\mathrm{H}^{+}$ions to react with $\mathrm{OH}^{-}$hydroxide to form water molecules. Considering the maximum value of $\mathrm{pH}$ (pH 11) reached during the durability tests, the amount of potassium $(\mathrm{K})$ in relation with $\mathrm{OH}^{-}$hydroxide $\left(\left[\mathrm{H}^{+}\right]\left[\mathrm{OH}^{-}\right]\right.$ $=14$ ) to form $\mathrm{KOH}$ was calculated and estimated at 0.14 $\mathrm{wt} \%$. Moreover, the comparison of the mass of samples before and after treatment indicates quasi identical values to within 2\% (Table 2). Actually, after drying at room temperature for $48 \mathrm{~h}$, samples lose about 1.5 and $2 \mathrm{wt} \%$

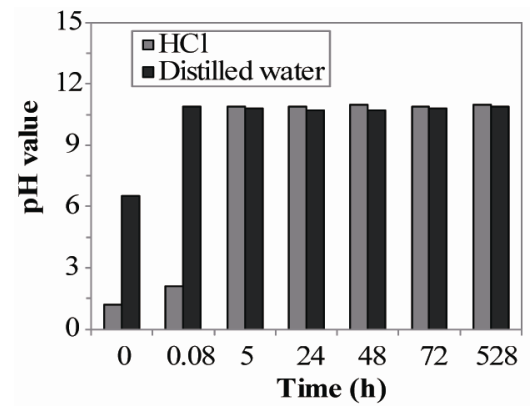

Figure 2. Variation of the pH value of aqueous solution (distilled water and $\mathrm{HCl}$ ) containing samples.

Table 2. Value of the weight and the compressive strength of samples before and after the durability tests.

\begin{tabular}{lcccc}
\hline \multicolumn{1}{c}{ Samples } & Untreated & $\begin{array}{c}\text { Distilled } \\
\text { water }\end{array}$ & $\begin{array}{c}\mathrm{HCl} \\
\text { solution }\end{array}$ & $\begin{array}{c}85 \% \\
\text { humidity }\end{array}$ \\
\hline Weight of sample (g) & 3.92 & 3.87 & 3.84 & 3.91 \\
Compressive strength (MPa) & $22 \pm 2$ & $19.5 \pm 3$ & $20 \pm 2$ & $21 \pm 1$ \\
\hline
\end{tabular}

for distilled water and acidic solution respectively suggesting the removal of very few species in solution.

As the amount of $\mathrm{KOH}$ determined basing on $\mathrm{pH}$ measurements $(0.14 \mathrm{wt} \%)$ is lower than the weight loss in both acid solution and distilled water, other reactions can take place. Some compounds obtained from the reaction of potassium with $\mathrm{CO}_{2}$ of atmosphere and representing respectively 1.86 and $1.36 \mathrm{wt} \%$ such as potassium carbonate $\left(\mathrm{K}_{2} \mathrm{CO}_{3}\right)$ and/or bicarbonate $\left(\mathrm{KHCO}_{3}\right)$ could be present or the geoplymer can release another $\mathrm{OH}^{-}$species if the total amount of $\mathrm{H}^{+}$is not sufficient to react with basic species. Moreover, elementary chemical analysis of solutions reveals the absence of $\mathrm{Al}$ and $\mathrm{Si}$ elements. Only $2 \mathrm{~mol} \%$ of $\mathrm{K}$ element were present in solution whatever the environment (neutral or acidic) consistent with results obtained by Vance et al. [14] and Aly et al. [9].

Figure 3 shows the evolution of the mass of samples submitted to controlled environment $\left(20^{\circ} \mathrm{C}, 85 \mathrm{H} \%\right)$. An increase of about $5 \%$ of sample weight is observed during the first seven days followed by a low raise of only $2 \%$ from 7 to 24 days.

This indicates a total gain of mass of $7 \%$ after 24 days of treatment. It is important to note that the mass continues to increase after the 24 days of study but with a very low rate of gain. Since the studied samples have same composition and same size and almost similar weight, we can assume that for a given sample, the mole number of $\mathrm{K}$ element present at the surface is equal to that determined by ICP-AES chemical analysis (Table 3 ). It has therefore been possible to estimate that the amount of potassium carbonate obtained from the reaction between $\mathrm{KOH}$ and $\mathrm{CO}_{2}$ is equal to $2 \mathrm{wt} \%$. As the total gains of

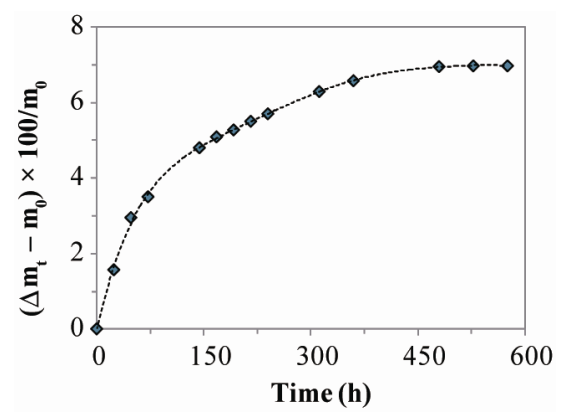

Figure 3. Variation of the weight gain of samples exposed in controlled environment $\left(20^{\circ} \mathrm{C} ; 85 \%\right.$ humidity $)\left(m_{t}\right.$ and $m_{0}$ represent the final and the initial weight respectively).

Table 3. Measured and calculated amounts of $\mathrm{K}$ element and of the corresponding species in aggressive solutions.

\begin{tabular}{|c|c|c|c|c|c|c|c|c|c|c|}
\hline \multirow{2}{*}{ Aggressive solution } & \multirow{2}{*}{$10^{4} \times$} & \multirow{2}{*}{$\mathrm{n}_{\mathrm{K} \text { measued }}(\mathrm{mol})$} & \multicolumn{3}{|c|}{$\mathrm{KOH}$} & \multicolumn{2}{|l|}{$\mathrm{KHCO}_{3}$} & \multirow{2}{*}{$10^{4} \times$} & \multirow{2}{*}{$\mathrm{n}_{\mathrm{K} \text { calculated }}(\mathrm{mol})$} & \multirow{2}{*}{ Uncertainty } \\
\hline & & & $10^{4} \times$ & $\mathrm{n}_{\text {КОН calculated }}(\mathrm{mol})$ & $\mathrm{wt} \% 10^{4} \times$ & $\mathrm{n}_{\mathrm{KHCO}_{3} \text { calculated }}(\mathrm{mol})$ & $\mathrm{wt} \%$ & & & \\
\hline $\mathrm{H}_{2} \mathrm{O}$ & & 7.3 & & 1 & 0.14 & 5.3 & 1.36 & & 6.3 & 0.13 \\
\hline $\mathrm{HCl}$ & & 6.5 & & 1 & 0.14 & 7.3 & 1.86 & & 8.3 & 0.27 \\
\hline
\end{tabular}


mass is $7 \mathrm{wt} \%$, by difference, the sample gains $5 \mathrm{wt} \%$ of mass by water permeation through the pores.

After drying at room temperature for $48 \mathrm{~h}$, the treated samples were evaluated by compression tests. The results compared with those of the sample which has not undergone durability tests are shown in Table 2. A slight decrease in mechanical properties is observed for samples immersed in aqueous media (distilled water and $\mathrm{HCl}$ ). But this result is not significant due to the error range. Furthermore, a humid atmosphere ( $85 \%$ humidity) does not seem to have a significant effect on mechanical properties. These results confirm the stability of these samples in aqueous media.

The surfaces of samples before and after durability treatments were observed by SEM in order to reveal the effect of these tests on samples (Figure 4).

Groups of aggregates of species of about $2 \mu \mathrm{m}$ were observed on the surface of the untreated sample (Figure 4(a)). The same phenomenon is observed with sample exposed in $85 \%$ of humidity showing more dispersed species on the surfaces (Figure 4(b)). This dispersion of species is related to the water content of the medium. The surface of samples submitted to the durability tests in distilled water and acidic solution (Figures 4(c) and (d)) display a quite smooth surface with a more pronounced effect with $\mathrm{HCl}$. This suggests the dissolution of species present on the surface of samples by the solutions. In view of the raise of the basicity of solutions (Figure 2) characteristic of the increase in hydroxide $\left(\mathrm{OH}^{-}\right)$or carbonate $\left(\mathrm{CO}_{3}^{2-}\right)$ ions and the identification of potassium element in solution by elementary chemical analysis (ICP-AES), the dissolved species would be potassium carbonate $\left(\mathrm{K}_{2} \mathrm{CO}_{3}\right)$ from the reaction between hydroxide potassium $(\mathrm{KOH})$ and carbon dioxide $\left(\mathrm{CO}_{2}\right)$ of atmosphere. It has been shown that during geopolymerization
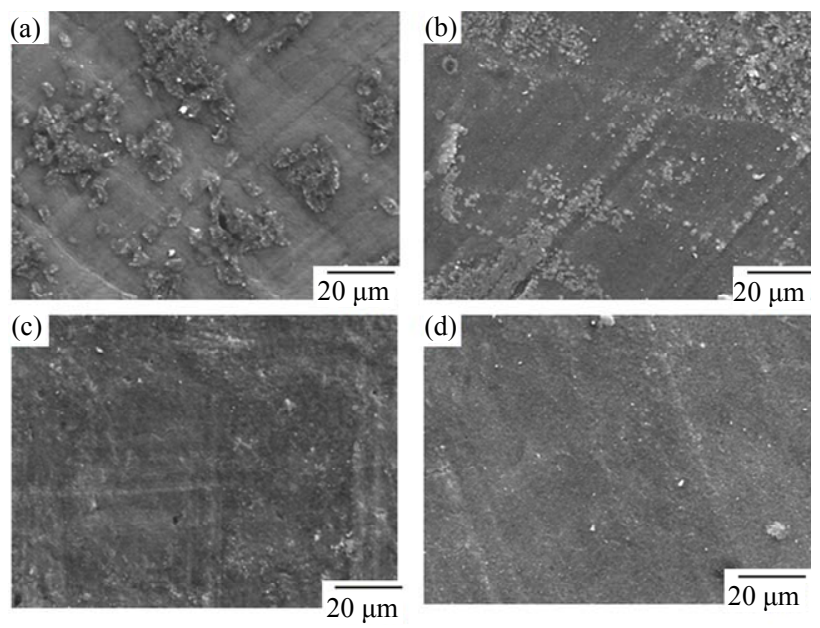

Figure 4. SEM photographs of sample surfaces according to the durability tests: (a) untreated, (b) controlled environment (85\% humidity), (c) distilled water and (d) $\mathrm{HCl}$. process, aluminum (Al) takes on a coordination of $4[15$, 16] i.e. $\left[\mathrm{Al}(\mathrm{OH})_{4}\right]^{-}$and $\mathrm{Na}^{+}$(or $\mathrm{K}^{+}$) maintains the charge balance in the geopolymer matrix. If the used alkali cation is in excess, it is deposited on the geopolymer surface. When exposed to air, a soluble sodium or potassium carbonate or bicarbonate could be formed [9].

The surface of the different samples appears not to be attacked confirming the stability of these materials in line with the acid resistance of geopolymer materials $[1,2]$.

The results of the elementary chemical analysis of the solution, the mechanical properties and the SEM observations of the surface of samples are consistent with the stability of such materials suggesting that the network of studied metakaolin-based geopolymer materials remain unchanged after the different treatments. The stability of these materials in aggressive environment could be related to the absence of $\mathrm{Ca}$ cation in the metakaolin used in this study. Actually, many of the durability problems posed by ordinary Portland cement are associated in one way or another with the calcium content of its main phases $[18,19]$. Fernandez-Jimenez et al. who have studied the durability of fly ash-based geopolymer materials concluded that the low $\mathrm{Ca}$ content in these materials is responsible for the strong resistance of these materials in acidic medium. These results are consistent with those obtained by Palomo et al. [1] in similar conditions. Bakharev et al. [2,3], and Van Jaarsveld et al. [11,20] in turn, reported that the stability of fly ash-based geopolymers in aggressive environments depended on the intrinsic ordering of the components within the aluminosilicate gel. They found that geopolymer materials prepared with sodium hydroxide are more crystalline and more stable in aggressive environments (such as sulphuric and acetic acid solutions) than when prepared with sodium silicate activators. They attributed these findings to the formation of a more stable cross-linked aluminosilicate polymer structure when the activator used was sodium hydroxide. On other study, Aly et al. [9] reported that the formulations of metakaolin-based geopolymers with $\mathrm{Si} / \mathrm{Al}$ of around 2 are more resistant in aggressive environment than those with higher $\mathrm{Si} / \mathrm{Al}$ ratios. They concluded that the low resistance of materials with higher $\mathrm{Si} / \mathrm{Al}$ ratios is related to a less polymerization in line with the interpretation of the compressive strength data of Rowles et al. [21]. Allahverdi et al. [5] who studied the corrosion of geopolymers in nitric acid assumed that reducing the amount of acid-soluble material, i.e. sodium, calcium and aluminum, would enhance acid resistance. However, Lloyd et al. [7] reported results which contradict the high acid resistance of geopolymers related to the low calcium content. They have studied the effect of calcium content in three types of fly ashes and concluded that the highcalcium ash was significantly more resistant to attack by sulphuric acid than any of the low calcium ashes sug- 
gesting that the presence of calcium does not in itself decrease the resistance to acids. They attributed this to the porosity and the ionic permeability of geopolymer containing calcium which is lower than that of samples with little or no calcium [8]. They also pointed out that the acid resistance of geopolymer materials depends on the nature and the $\mathrm{pH}$ value of the acid, for solutions of weak acids and low $\mathrm{pH}$ value can be far more aggressive towards cementitious materials than strong acids of the same $\mathrm{pH}[4,7,22]$. The same authors [7] also reported that the increase in the dissolved silica content improved the acid resistance in relation with the raise of gel volume and ratio of silicon to aluminum [23]. They assumed that the increase of silica amount produces a denser corroded layer, and hinders the rate of degradation by reducing the extent of damage incurred by the aluminosilicate framework structure with the removal of each of the aluminum atoms under acid attack [24]. This is in contradiction with results obtained by Aly et al. [9] abovementioned, but is in line with our result in relation with the reinforcement of geopolymer materials by $12 \mathrm{wt} \%$ of sand addition which raises the $\mathrm{Si} / \mathrm{Al}$ ration from 1.33 to 2.4. Actually, the SEM observation of the untreated sample does not reveal the presence of sand grains which mean diameter is $90 \mu \mathrm{m}$ suggesting a total dissolution (Figure 5).

The differences brought up in various studies on geopolymer durability could be related not only to the composition of raw materials used to form geopolymers, but also to the applied methods of durability tests, for, in the case of the work of Lloyd et al. [7], the $\mathrm{pH}$ value was adjusted daily by the addition of concentrated acid in order to maintain constant the value all along the test, unlike most of tests in which the $\mathrm{pH}$ of acid solution was not adjusted as in the case of this study.

All this suggests that the study of the durability of geopolymer materials in aggressive environment remains complex and require many investigations taking into account various parameters (such as the nature and the $\mathrm{pH}$ of the acid solution, the composition of the raw materials, the duration and the applied method of the test $\cdots$ ) before making a general conclusion on their acid resistance.

\section{Conclusion}

The tubes of geopolymers reinforced with sand show good

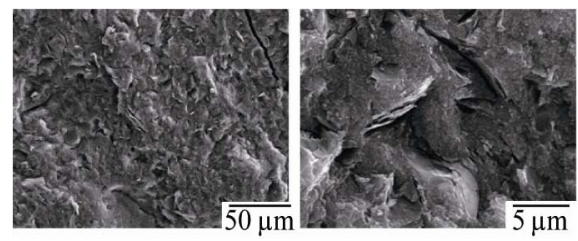

Figure 5. SEM micrographs of the fracture of a sample which does not undergo durability tests. resistance when they are subjected to acid, neutral or humid environment. Actually, mechanical properties of these materials do not change after durability tests. SEM observations reveal the presence of soluble species on the surface which would be hydroxide or carbonate potassium due to the increase of the $\mathrm{pH}$ value and the presence of potassium ions in the solution evidenced par ICP-AES analysis. Moreover, the surface of samples appears not to be attacked confirming the stability of these materials.

\section{REFERENCES}

[1] A. Palomo, M. T. Blanco-Varela, M. L. Granizo, F. Puertas, T. Vazquez and M. W. Grutzeck, "Chemical Stability of Cementitious Materials Based on Metakaolin," Cement and Concrete Research, Vol. 29, No. 7, 1999, pp. $997-$ 1004. doi:10.1016/S0008-8846(99)00074-5

[2] T. Bakharev, "Resistance of Geopolymer Materials to Acid Attack," Cement and Concrete Research, Vol. 35, No. 4, 2005, pp. 658-670. doi:10.1016/j.cemconres.2004.06.005

[3] T. Bakharev, J. G. Sanjayan and Y.-B. Cheng, "Resistance of Alkali-Activated Slag Concrete to Acid Attack," Cement and Concrete Research, Vol. 33, No. 10, 2003, pp. 1607-1611. doi:10.1016/S0008-8846(03)00125-X

[4] C. Shi and J. A. Stegemann, "Acid Corrosion Resistance of Different Cementing Materials," Cement and Concrete Research, Vol. 30, No. 5, 2000, pp. 803-808. doi:10.1016/S0008-8846(00)00234-9

[5] A. Allahverdi and F. Škvára, "Nitirc Acid Attack on Hardened Paste of Geopolymeric Cements: Part 1," Ceramics-Silikáty, Vol. 45, No. 4, 2001, pp. 81-88.

[6] J. Davidovits, "Synthetic Mineral Polymer Compound of the Silicoaluminates Family and Preparation Process," US Patent No. 4472199, 1984.

[7] R. R. Lloyd, J. L. Provis and J. S. J. van Deventer, “Acid Resistance of Inorganic Polymer Binders. 1. Corrosion Rate," Materials and Structures, Vol. 45, No. 1-2, 2012, pp. 1-14. doi:10.1617/s11527-011-9744-7

[8] R. R. Lloyd, J. L. Provis, K. J. Smeaton and J. S. J. van Deventer, "Spatial Distribution of Pores in Fly Ash-Based Inorganic Polymer Gels Visualized by Wood's Metal Intrusion," Microporous and Mesoporous Materials, Vol. 126, No. 1-2, 2009, pp. 32-39. doi:10.1016/j.micromeso.2009.05.016

[9] Z. Aly, E. R. Vance, D. S. Perera, J. V. Hanna, C. S. Griffith, J. Davis and D. Durce, "Aqueous Leachability-Based Geopolymers with Molar Ratios of $\mathrm{Si} / \mathrm{Al}=1.5$ - 4," Journal of Nuclear Materials, Vol. 378, No. 2, 2008, pp. 172-179. doi:10.1016/i.jnucmat.2008.06.015

[10] T. Bakharev, "Durability of Geopolymer Materials in Sodium and Magnesium Sulfate Solutions," Cement and Concrete Research, Vol. 35, No. 6, 2005, pp. 1233-1246. doi:10.1016/j.cemconres.2004.09.002

[11] J. G. S. van Jaarsveld and J. S. J. van Deventer, "Effect of the Alkali Metal Activator on the Properties of Fly AshBased Geopolymers," Industrial \& Engineering Chemis- 
try Research, Vol. 38, No. 10, 1999, pp. 3932-3941. doi:10.1021/ie980804b

[12] A. V. McCormick and T. Bell, "The Solution Chemistry of Zeolite Precursors," Catalysis Reviews: Science and Engineering, Vol. 31, No. 1-2, 1989, pp. 97-127. doi:10.1080/01614948909351349

[13] E. Prud'homme, P. Michaud, E. Joussein, C. Peyratout, A. Smith and S. Rossignol, "In Situ Inorganic Foams Prepared from Various Clays at Low Temperature," Applied Clay Science, Vol. 51, No. 1-2, 2011, pp. 15-22. doi:10.1016/j.clay.2010.10.016

[14] E. R. Vance, D. S. Perera, Z. Aly, M. Blackford, Y. Zhang, Z. Zhang, M. Rowles, J. V. Hanna, K. J. Pike, J. Davis and O. Uchida, "Solid State Chemistry Phenomena in Geopolymers with $\mathrm{Si} / \mathrm{Al} \sim 2$," Proceedings of the GGC 2005 International Workshop on Geopolymers and Geopolymer Concrete, Perth, 28-29 September 2005.

[15] P. G. McCornick and J. T. Gourley, "Inorganic Polymers-A New Material for the New Millennium," Materials Australian, Vol. 23, 2000, pp. 16-18.

[16] D. Khale and R. Chaudhary, "Mechanism of Geopolymerization and Factors Influencing Its Development: A Review," Journal of Materials Science, Vol. 42, No. 3, 2007, pp. 729-746. doi:10.1007/s10853-006-0401-4

[17] X. Zhaohui and X. Yunping, "Hardening Mechanisms of an Alkaline-Activated Class F Fly Ash," Cement and Concrete Research, Vol. 31, No. 9, 2001, pp. 1245-1249.
doi:10.1016/S0008-8846(01)00571-3

[18] V. Johansen, N. Thaulow and J. Skalny. "Simultaneous Presence of Alkali-Silica Gel and Ettringite in Concrete," Advances in Cement Research, Vol. 5, 1993, pp. 23-29.

[19] C. D. Lawrence, "Materials Science of Concrete IV," In: J. Skalny and S. Mindess, Eds., American Ceramic Society, Westerville, 1995.

[20] J. G. S. Van Jaarsveld, J. S. J. Van Deventer and L. Lorenzen, "Factors affecting the Immobilization of Metals in Geopolymerized Fly Ash," Metallurgical and Materials Transactions B: Process Metallurgy and Materials Processing Science, Vol. 29, 1998, pp. 283-291.

[21] M. Rowles and B. O'Connor, "Chemical Optimisation of the Compressive Strength of Aluminosilicate Geopolymers Synthesised by Sodium Silicate Activation of Metakaolinite," Journal of Materials Chemistry, Vol. 13, No. 5, 2003, pp. 1161-1165. doi:10.1039/b212629j

[22] R. E. Beddoe, H. W. Dorner, "Modelling Acid Attack on Concrete: Part I. The Essential Mechanisms," Cement and Concrete Research, Vol. 35, No. 12, 2005, pp. 2333-2339. doi:10.1016/j.cemconres.2005.04.002

[23] R. R. Lloyd, "The Durability of Inorganic Polymer Cements," Ph.D. Thesis, University of Melbourne, Melbourne, 2008.

[24] R. L. Hartman and H. S. Fogler, "Understanding the Dissolution of Zeolites," Langmuir, Vol. 23, No. 10, 2007, pp. 5477-5484. doi:10.1021/la063699g 